\title{
Chloralose Alters Both Basal Hemodynamics and Cardiovascular Responses to Alveolar Hypoxia in Chronically Instrumented, Spontaneously Breathing Lambs ${ }^{1}$
}

\author{
ROBERT F. COVERT, ${ }^{2}$ WILLA H. DRUMMOND, PHYLLIS A. GIMOTTY, ${ }^{3}$ AND \\ RANDOLPH L. CARTER \\ Divisions of Neonatology and Biostatistics, Departments of Pediatrics, Physiology, and Statistics, University of \\ Florida College of Medicine, Box J-296/JHM Health Center, Gainesville, Florida 32610
}

\begin{abstract}
We studied the effects of chloralose anesthesia on the basal hemodynamic state and on the cardiovascular response to alveolar hypoxia in chronically instrumented, spontaneously breathing lambs, compared with responses to the saline vehicle. Chloralose significantly increased heart rate $(23 \%)$, mean systemic arterial pressure $(11 \%)$, systemic vascular resistance $(21 \%)$, mean pulmonary arterial pressure $(23 \%)$, and pulmonary vascular resistance $(46 \%)(n=30, p<0.05$, ANOVA). These changes were unrelated to baseline tone of the circulation, cardiac output, mean left atrial pressure, or physiologically important changes in arterial blood gas tensions. In addition, chloralose-treated lambs had increased heart rate, systemic vascular resistance, and pulmonary vascular resistance compared to controls during alveolar hypoxia (13$15 \% \mathrm{FiO}_{2}$ ). Importantly, chloralose-treated lambs did not increase their cardiac output during alveolar hypoxia as did control lambs. During hypoxia, systemic vascular resistance remained elevated in chloralose-treated lambs, but declined in control lambs. Chloralose has been recommended as an ideal anesthetic agent for cardiovascular experimentation. Our data suggest that chloralose-induced alterations in basal hemodynamics and in cardiovascular responses to alveolar hypoxia represent an uncontrolled variable in acute experimental studies. Complex cardiovascular alterations caused by anesthesia should be considered in experimental design. (Pediatr Res 25:389-395, 1989)
\end{abstract}

\section{Abbreviations}

PVR, pulmonary vascular resistance

SVR, systemic vascular resistance

Received May 31, 1988: accepted November 22, 1988.

Correspondence and reprint requests to Robert F. Covert, M.D., Assistant Professor, Department of Pediatrics, Division of Neonatology, Michael Reese Hospital and Medical Center, 12th Floor KC, Lake Shore Drive at 31st Street, Chicago, IL 60616.

Funded by a grant from the American and the Florida Heart Associations, and by the Division of Neonatology, Department of Pediatrics, University of Florida College of Medicine.

1 Presented in part at the 37th Annual Fall Meeting of the American Physiological Society in New Orleans, LA, on October 8, 1986, and at the Southern Society for Pediatric Research in New Orleans, LA, on February 5, 1988.

${ }^{2}$ Present address: University of Chicago Pritzker School of Medicine, and Michael Reese Hospital and Medical Center, Chicago, IL 60616.

${ }_{3}^{3}$ Present address: Michigan Cancer Foundation, 110 E. Warren Avenue, Detroit, MI 48201 . $\alpha$-chloralose, an anesthetic agent used exclusively in animal research, has been considered an ideal anesthetic for cardiovascular research because it appears to lack adverse cardiovascular effects $(1,2)$. As such, chloralose is frequently used in acute cardiovascular experimentation without a control for its potential effects.

Chloralose $\left(\mathrm{C}_{8} \mathrm{H}_{11} \mathrm{Cl}_{3} \mathrm{O}_{6}\right)$ is the main product of the condensation of glucose with anhydrous chloral in the presence of sulfuric acid $(3,4)$. The metabolic products of chloralose are chloral and chloraldehyde; the latter is primarily metabolized to the hypnotic agent trichloroethanol. Chloralose is often used for anesthesia in combination with solvents, such as borate or polyethylene glycol, that may be uncontrolled and unreported. Chloralose anesthesia is often supplemented with other agents, such as morphine or urethane.

Evidence (5-7) suggests that some anesthetic agents have a greater effect on hemodynamics and cardiovascular responses than has been previously appreciated. Chronically instrumented animal models $(6-11)$ allow the opportunity for physiologic studies to be performed without anesthesia and permit the effects of an anesthetic agent to be compared with a conscious control, using a paired experimental design.

No studies have focused on the cardiovascular effects of chloralose in animals chronically instrumented for measurements of cardiac output and vascular pressures in both the systemic and pulmonary circulations. This study was designed to measure the effects of chloralose on basal hemodynamics and on the cardiovascular response to alveolar hypoxia during spontaneous ventilation. In the following experiments, each chronically instrumented lamb acts as its own control to test the null hypotheses that: 1) chloralose does not alter basal systemic and pulmonary hemodynamics, and 2) chloralose does not alter the cardiovascular response to alveolar hypoxia.

\section{MATERIALS AND METHODS}

Instrumentation. Newborn lambs underwent chronic instrumentation as previously described $(8,9)$ while anesthetized with halothane delivered by a small-animal ventilator. Fluid-filled vascular catheters (Tygon Micro-Bore plastic tubing, Norton Performance Plastics, Akron, $\mathrm{OH}$ ) with an external plastic collar were advanced to the descending aorta and inferior vena cava through the dorsalis pedis artery and superficial veins exposed by an incision in the lower hindlimb.

A left-sided thoracotomy and pericardiotomy were performed to ligate the ductus arteriosus, to place a precalibrated electromagnetic flow transducer (Howell Instruments, Camarillo, CA) 
around the main pulmonary artery, and to place vascular catheters by direct puncture into the main pulmonary artery distal to the flow transducer and into the left atrium. The transducer cable and catheters were exteriorized to a canvas pouch on the lamb's flank, and the chest wall was closed in layers. During the procedure, care was taken to avoid injury to the long thoracic, vagus, and phrenic nerves and to avoid external compression of the left anterior descending coronary artery by the flow transducer when exteriorizing the cable.

After recovery from anesthesia, lambs were returned to their ewes to recover. Postoperative analgesia was not used, because experience in our laboratory has shown that the sedative side effects impair ewe-to-lamb rebonding and interfere with the lamb's ability to walk and to suckle. Vascular catheters were cleared and refilled with heparin daily. Satisfactory catheter positions and patency were confirmed by postmortem examination in each lamb.

Cardiovascular Measurements and Calculations. Mean systemic arterial pressure ( $\overline{\mathrm{SAP}})$, mean pulmonary arterial pressure $(\overline{\mathrm{PAP}})$, and mean left atrial pressure $(\overline{\mathrm{LAP}})$ were measured with Gould-Statham P23ID transducers. Pulmonary artery blood flow was measured with Gould-Statham SP2202 flowmeters. All physiologic measurements were continuously recorded on a Gould 2800 physiologic recorder. Heart rate was determined from the phasic pulmonary blood flow trace. Vascular pressure transducers and amplifiers were calibrated before each study with a mercury manometer (Baum, Inc., Copiague, NY); flow transducers were precalibrated before each implantation using saline under gravity flow to a sensitivity which gave a linear reading at the flow values observed. Zero reference for the flow transducer was taken as the end-diastolic flow value in the main pulmonary artery (10) and for vascular pressures was taken at estimated left atrial height. Zero references were checked before each point of data collection. Respiratory rate, arterial blood gas tensions and $\mathrm{pH}$ were measured at the points defined in the protocol. A Corning 165 blood gas analyzer (Ciba Corning Diagnostics, Medfield, MA) was used at $37^{\circ} \mathrm{C}$ to measure arterial blood gas tensions and $\mathrm{pH}$ which were then mathematically corrected for the lamb's measured rectal temperature (Yellow Springs thermistor probe, Yellow Springs Instruments, $\mathrm{OH}$ ).

Cardiac output $(\mathrm{CO})$ was calculated as $\mathrm{mL} / \mathrm{min}$ of pulmonary blood flow $/ \mathrm{kg}$ of body wt. PVR and SVR were calculated using the formulas: PVR $=(\overline{\mathrm{PAP}}-\overline{\mathrm{LAP}}) / \mathrm{CO}$ and $\mathrm{SVR}=\overline{\mathrm{SAP}} / \mathrm{CO}$. As an index of relative changes in the resistance of the two circulations, we calculated the ratio of pulmonary to systemic vascular resistance (PVR/SVR).

Drug Preparation. $\alpha$-chloralose (Calbiochem-Behring Corp., La Jolla, CA) was prepared with sodium chloride and distilled water to give a fixed concentration of $7.5 \mathrm{mg} / \mathrm{mL}$ as previously described (9). No other solvent or vehicle was used, and anesthesia was not supplemented with another drug. For control studies, the vehicle was prepared with the same amount of sodium chloride and distilled water, resulting in $64 \%$ of normal saline.

Health Criteria. All animals had recovered from surgery for at least $2 \mathrm{~d}$ and were considered healthy. To be eligible for study, each animal was required to meet specific health criteria (9).

Study Protocols. Lambs were studied while initially awake, spontaneously breathing room air, resting quietly upright in a sling, and with all instrumentation appropriately attached. Each lamb had paired control and anesthetic studies performed from $1-5 \mathrm{~d}$ apart.

Basal hemodynamics protocol. Thirty paired studies were performed in 24 mixed breed lambs of either sex (10 female, 14 male). Baseline values for each hemodynamic variable were the mean of four measurements taken at 5-min intervals in the awake lamb. Animals then received either chloralose $(30 \mathrm{mg} / \mathrm{kg}$, or $4 \mathrm{~mL} / \mathrm{kg}$ intravenously) or an equal vol of saline vehicle at $7.6 \mathrm{~mL} / \mathrm{min}$, infused over approximately $3 \mathrm{~min}$ through an intravenous filter (Millipore Corp., Bedford, MA) by an electron- ically timed infusion pump (Harvard Apparatus Co., Dover, MA). Hemodynamic data were then collected every 5 min. Arterial blood gas tensions, $\mathrm{pH}$, and respiratory rate were measured at baseline and at 15 and 30 min after both chloralose and control vehicle infusion.

We observed 20 lamb pairs for $30 \mathrm{~min}$ and an additional 10 lamb pairs for $15 \mathrm{~min}$. Treatment order was alternated so that 15 study pairs received control vehicle first and 15 received chloralose first. Studies were performed 2 to 29 d (mean, 8 d) after the thoracotomy and at postnatal ages of 4 to $32 \mathrm{~d}$ (mean, $11 \mathrm{~d}$ ). Lambs weighed 2.4 to $9.7 \mathrm{~kg}$ (mean, $5.2 \mathrm{~kg}$ ).

Each lamb then went on to a follow-up protocol to evaluate the influence of chloralose on various cardiovascular reflexes such as the effect of chloralose on the response to $\alpha$-adrenergic agents as previously reported (9) or on the pulmonary vascular response to alveolar hypoxia as reported here. A single dose of $30 \mathrm{mg} / \mathrm{kg}$ was chosen so that: 1 ) animals would have a similar exposure to a commonly used dose of chloralose (as is usually done for acute experiments), 2) mechanical ventilation would not be necessary, and 3) the lambs would awaken by the end of the $\mathrm{d}$. Thus, no attempt was made to determine a dose-response curve nor to achieve a specific depth of anesthesia.

Response to alveolar hypoxia protocol. Six lambs of either sex (four female, two male) were studied once each in paired experiments. After baseline measurements (base 1), the animals then received either chloralose or vehicle as previously described. At 30 min later, hemodynamic variables were remeasured (base 2).

Alveolar hypoxia was induced by allowing the lambs to breathe blended gases (Simet blender, Veriflow Corp., Richmond, CA) from a large plastic hood secured with a nonconstricting tie around the lamb's neck. The gas mixture consisted of nitrogen (flow rate $9 \mathrm{~L} / \mathrm{min}$ ) and oxygen $(1.5$ to $2 \mathrm{~L} / \mathrm{min}$ ), adjusted to obtain a stable $\mathrm{FiO}_{2}$, and was continuously measured with an inline Ventronics Oxygen Sensor with Micro-Fuel Cell (Temecula, CA) interfaced with a Pneumogard monitor (Novametrix Medical System, Inc., Wallingford, CT). Each lamb received a stable $\mathrm{FiO}_{2}$ between 13-15\%; although the group ranged in $\mathrm{FiO}_{2}$ values, individual lambs received the same $\mathrm{FiO}_{2}$ during both the anesthesia and control experiments.

During alveolar hypoxia, hemodynamic measurements were made every $5 \mathrm{~min}$ for $20 \mathrm{~min}$. Arterial blood gas tensions, $\mathrm{pH}$,

Table 1. Arterial blood gas tensions, $p H$, and respiratory rate before and after chloralose or control vehicle in spontaneously breathing lambs*

\begin{tabular}{|c|c|c|c|c|}
\hline \multirow[b]{2}{*}{ Variable } & \multicolumn{3}{|c|}{ Timet } & \multirow[b]{2}{*}{$p$ value } \\
\hline & Baseline & $15 \min$ & $30 \mathrm{~min}$ & \\
\hline$n$ pairs & 30 & 30 & 20 & \\
\hline \multicolumn{5}{|l|}{$\mathrm{Pa}_{\mathrm{O}_{2}}(\mathrm{~mm} \mathrm{Hg})$} \\
\hline Control & $87 \pm 2$ & $86 \pm 2$ & $87 \pm 2$ & 0.02 \\
\hline Chloralose & $86 \pm 2$ & $84 \pm 2$ & $75 \pm 3$ & \\
\hline \multicolumn{5}{|l|}{$\mathrm{Pa}_{\mathrm{CO}_{2}}(\mathrm{~mm} \mathrm{Hg})$} \\
\hline Control & $43 \pm 1$ & $43 \pm 1$ & $40 \pm 1$ & NS \\
\hline $\begin{array}{l}\text { Chloralose } \\
\mathrm{pH}\end{array}$ & $44 \pm 1$ & $44 \pm 1$ & $42 \pm 1$ & \\
\hline Control & $7.37 \pm 0.01$ & $7.35 \pm 0.01$ & $7.37 \pm 0.01$ & 0.04 \\
\hline Chloralose & $7.36 \pm 0.01$ & $7.34 \pm 0.01$ & $7.33 \pm 0.01$ & \\
\hline \multicolumn{5}{|l|}{$\begin{array}{l}\text { Respiratory rate } \\
\text { (breaths/ } \\
\text { min) }\end{array}$} \\
\hline Control & $63 \pm 4$ & $62 \pm 4$ & $65 \pm 5$ & 0.01 \\
\hline Chloralose & $62 \pm 3$ & $54 \pm 2$ & $51 \pm 3$ & \\
\hline
\end{tabular}

$*$ Data are mean \pm SEM.

$\dagger$ Baseline refers to initial unaltered baseline, and 15 and 30 min refer to time elapsed after chloralose or control vehicle.

$\ddagger$ Refers to treatment-time interaction (ANOVA); that is, $p<0.05$ indicates that chloralose and control group values diverged with time. 
and respiratory rate were measured in both groups at base 1, base 2, and at 10 and 20 min after onset of hypoxia. Three lambs received chloralose first and three received control vehicle first. Studies were performed 2 to $12 \mathrm{~d}$ (mean, $7 \mathrm{~d}$ ) after the thoracotomy and at postnatal ages of 4 to $22 \mathrm{~d}$ (mean, $7 \mathrm{~d}$ ). Lambs weighed 4.2 to $7.8 \mathrm{~kg}$ (mean, $5.8 \mathrm{~kg}$ ). Different lambs were studied in this protocol than were studied in the basal protocol.

Animal procedures were approved by the All University Committee on the Care and Use of Laboratory Animals.

Statistics. Basal hemodynamics. A multivariate ANOVA for repeated measures (Statistical Analysis System, SAS Institute, Cary, NC) was used to test each cardiopulmonary measurement. This ANOVA evaluated three factors: treatment (chloralose ver- sus control), time (sequential related data over time), and order (chloralose first versus control first) as well as interactions between these factors. A treatment-time interaction $(p<0.05)$ was reported as a significant difference between treatments as both groups began the study with equivalent base 1 values by paired Student's $t$ test.

Response to alveolar hypoxia. Similar multivariate ANOVA for repeated measures were designed to evaluate independently whether a treatment effect existed either before or after alveolar hypoxia. Thus, the first ANOVA for a cardiopulmonary variable included the data of base 1 and base 2 for both chloralose and control groups; when a treatment-time interaction $(p<0.05)$ for a cardiopulmonary variable was detected, single point compari-
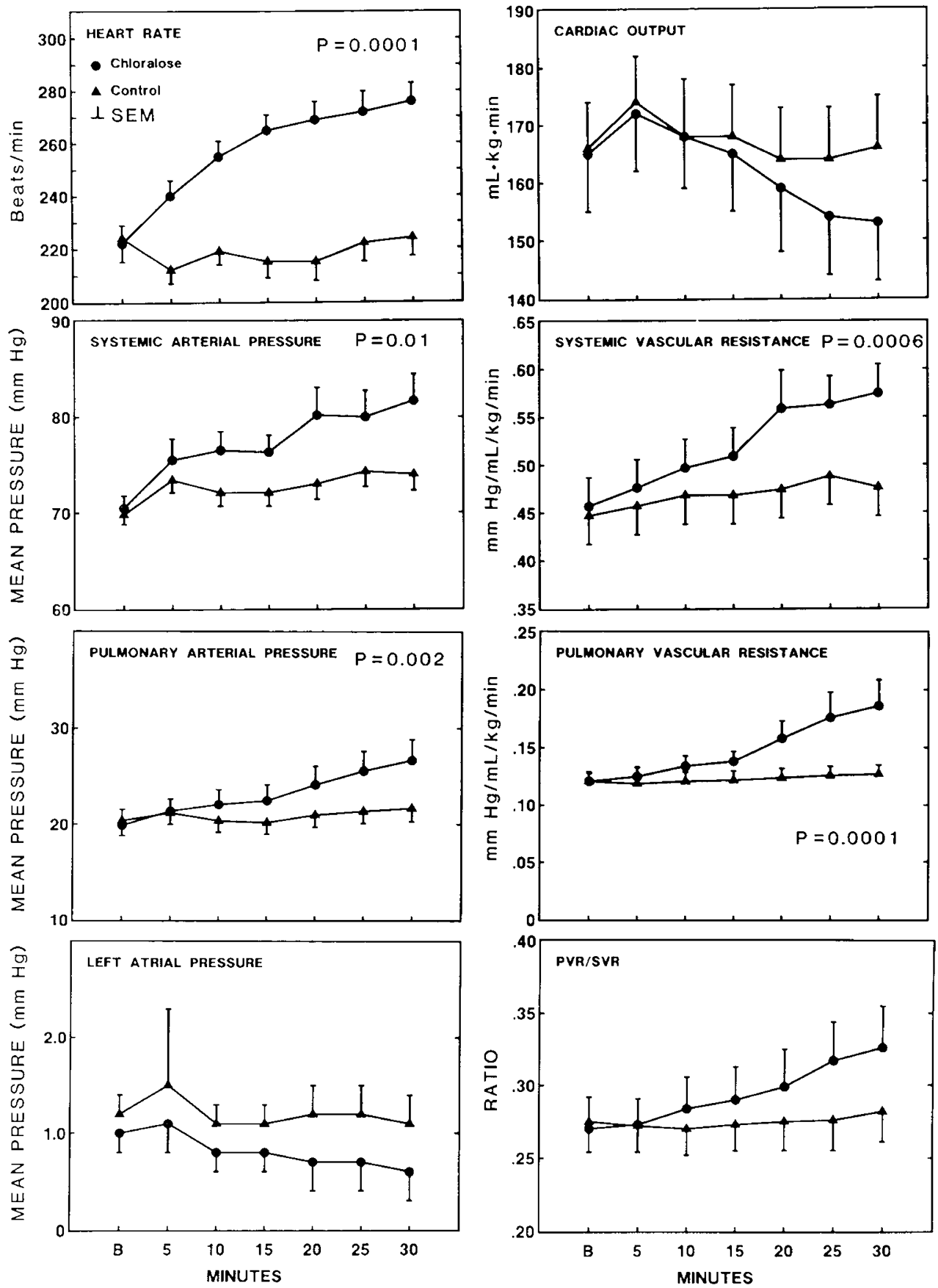

Fig. 1. Hemodynamics after chloralose $(30 \mathrm{mg} / \mathrm{kg}$ intravenously, -) or control saline vehicle $(\mathbf{\Lambda})$ in spontaneously breathing lambs. All hemodynamic values of initial conscious baseline (B) did not differ. Data are mean \pm SEM. Statistically significant differences (ANOVA, $p<0.05$ ) between treatments across time are noted by the appropriate $p$ value in the panels; $n=30$ paired studies in 24 lambs for 15 min and 20 paired studies for $30 \mathrm{~min}$. 
sons at base 1 and base 2 with the paired Student's $t$ test were performed to detect whether a difference was induced by anesthetic treatment. Cardiopulmonary variables at base 1 were similar between treatment groups.

The second ANOVA included the data for each 5-min observation during alveolar hypoxia for both treatments. Chloralose versus control data were reported as significantly different when the ANOVA detected either a treatment effect $(p<0.05)$ or a time-treatment interaction $(p<0.05)$. Significant interactions were followed by single point comparisons with the paired Student's $t$ test protected by the Bonferroni correction.

Data were depicted as the mean and the SEM.

\section{RESULTS}

General Observations. Each lamb was unarousable by 5 to 15 min after chloralose injection. Anesthesia-induced excitability was absent, and auditory sensitivity was minimal. No lamb had apnea. The myoclonus which has been described with chloralose anesthesia was observed in many lambs; however, the myoclonus was usually mild, did not interfere with hemodynamic measurements, and was apparent only after chloralose-induced alterations in hemodynamics occurred. All lambs remained quiet without agitation at the range of $\mathrm{FiO}_{2}$ used for hypoxia studies. Chloralose-anesthetized lambs recovered to a wakeful state in 4 to $6 \mathrm{~h}$.

Basal Hemodynamics. Arterial blood gas tensions/respiratory rate. Arterial oxygen tension decreased in the chloralose group compared to control by $30 \mathrm{~min}(75 \pm 3$ versus $87 \pm 2 \mathrm{~mm} \mathrm{Hg}$, $p=0.02$ ) (Table 1). No difference in arterial carbon dioxide tension was observed between groups or across time. Arterial pH decreased in the chloralose group by $30 \mathrm{~min}(7.33 \pm 0.01$ versus $7.37 \pm 0.01, p=0.04$ ) (Table 1). Respiratory rate slowed in the chloralose group compared to control by $30 \mathrm{~min}(51 \pm 3$ versus $65 \pm 5, p=0.01$ ) (Table 1). Changes in hemodynamic variables were detected before differences in arterial blood gas tensions developed.

Heart rate and cardiac function. Chloralose increased heart rate by $23 \%$ at $30 \mathrm{~min}$ compared to control $(p=0.0001)$ (Fig. 1). Cardiac output and mean left atrial pressure did not change and did not differ between treatments (Fig. 1).

Svstemic circulation. Mean systemic arterial pressure increased by $11 \%$ in the chloralose group at $30 \mathrm{~min}$ compared to control $(p=0.01)$ (Fig. 1). At $30 \mathrm{~min}$, the chloralose group had a $21 \%$ increase in systemic vascular resistance $(p=0.0006)$ (Fig. 1).

Pulmonarv circulation. Mean pulmonary arterial pressure increased by $23 \%$ in the chloralose group at $30 \mathrm{~min}$ compared to control $(p=0.002)$ (Fig. 1). Pulmonary vascular resistance increased by $46 \%$ in the chloralose group at $30 \mathrm{~min}(p=0.0001)$ (Fig. 1).

PVR/SVR ratio. No difference between groups or across time was detected in the ratio PVR/SVR (Fig. 1).

Response to alveolar hypoxia. Arterial blood gas tensions/ respiratory rate. No difference in arterial oxygen tension, carbon dioxide tension, or $\mathrm{pH}$ was detected at either base 1 or base 2 (Table 2). After alveolar hypoxia, arterial oxygen tension was lower in the chloralose group by 4 to $5 \mathrm{~mm} \mathrm{Hg}$ at 10 and 20 min $(p=0.04)$ when comapred to control (Table 2). After alveolar hypoxia, no difference between groups in arterial carbon dioxide tension or $\mathrm{pH}$ was detected. Respiratory rate was slower in the chloralose group at both base $2(p=0.002)$ and after hypoxia $(p=0.003)$ when compared to control. Once again, changes in hemodynamic variables consistently were detected before differences in arterial oxygen tension developed between treatments.

Hearl rate and cardiac function. Chloralose increased heart rate $34 \%$ at base 2 ( $p=0.0001$ ) (Fig. 2). As expected, alveolar hypoxia further increased heart rate in both treatment groups, but the chloralose group continued to have a higher heart rate after hypoxia compared to control $(19 \%$ at $20 \mathrm{~min}, p=0.01)$.
Table 2. Arterial blood gas tensions, $p H$, and respiratory rate before and after alveolar hypoxia in chloralose-or control vehicle-treated spontaneously breathing lambs*

\begin{tabular}{lcccc}
\hline & \multicolumn{4}{c}{ Time } \\
\cline { 2 - 5 }$\quad$ Variable & Base 1 & Base 2 & $10 \mathrm{~min}$ & $20 \mathrm{~min}$ \\
\hline $\mathrm{PaO}_{2}(\mathrm{~mm} \mathrm{Hg})$ & & & & \\
$\quad$ Control & $88 \pm 2$ & $87 \pm 2$ & $54 \pm 3$ & $47 \pm 2$ \\
$\quad$ Chloralose & $86 \pm 2$ & $80 \pm 3$ & $50 \pm 2 \dagger$ & $42 \pm 2 \dagger$ \\
$\mathrm{PaCO}_{2}(\mathrm{~mm} \mathrm{Hg})$ & & & & \\
$\quad$ Control & $44 \pm 2$ & $40 \pm 2$ & $40 \pm 2$ & $40 \pm 2$ \\
$\quad$ Chloralose & $48 \pm 1$ & $42 \pm 2$ & $39 \pm 2$ & $40 \pm 1$ \\
$\mathrm{pH}$ & & & & \\
$\quad$ Control & $7.39 \pm 0.01$ & $7.39 \pm 0.02$ & $7.41 \pm 0.01$ & $7.38 \pm 0.02$ \\
$\quad$ Chloralose & $7.37 \pm 0.01$ & $7.33 \pm 0.02$ & $7.37 \pm 0.01$ & $7.38 \pm 0.01$ \\
Respiratory rate & & & & \\
$\quad$ (breaths/ & & & & \\
$\quad$ min) & & & & \\
Control & $61 \pm 3$ & $61 \pm 3$ & $77 \pm 5$ & $82 \pm 6$ \\
Chloralose & $61 \pm 4$ & $45 \pm 3 \ddagger$ & $49 \pm 4 \ddagger$ & $55 \pm 3 \ddagger$ \\
\hline
\end{tabular}

* Data are mean \pm SEM, $n=6$ paired studies. Base 1 refers to initial unaltered baseline, base 2 refers to prehypoxia baseline after either chloralose or control vehicle, and 10 and $20 \mathrm{~min}$ refer to posthypoxia data.

$\dagger p<0.05 v$ s. control, ANOVA.

$\ddagger p<0.005$ vs. control, ANOVA.

Significant differences also existed between chloralose and control groups in cardiac output (Fig. 2). At base 2, the chloralose group had a $25 \%$ lower cardiac output $(p=0.01)$. During alveolar hypoxia, the control group demonstrated the expected rise in cardiac output, but the chloralose group did not, augmenting the difference between treatments $37 \%$ at $20 \mathrm{~min}, p=$ $0.006)$. Mean left atrial pressure did not change throughout the study and did not differ between treatments (Fig. 2).

Systemic circulation. Despite the cardiac output differences, mean systemic arterial pressure did not change throughout the study and did not differ between treatments (Fig. 2). Thus, systemic vascular resistance was $41 \%$ higher in the chloralose group at base 2 compared to control ( $p=0.03$ ) (Fig. 2). After hypoxia, systemic vascular resistance declined in the control group, but remained elevated in the chloralose group, leading to significant differences between treatments. Follow-up testing demonstrated that the chloralose group had an increase in systemic vascular resistance over control at both $15(p=0.01)$ and $20 \min (75 \%$ higher, $p=0.008)$.

Pulmonary circulation. No difference between groups was detected in mean pulmonary arterial pressure at base 1 or base 2 (Fig. 2). As expected, mean pulmonary arterial pressure increased in both treatment groups during alveolar hypoxia and no difference between groups was detected. At base 2, pulmonary vascular resistance was $28 \%$ higher in the chloralose group compared to control ( $p=0.02$ ) (Fig. 2). During subsequent alveolar hypoxia, pulmonary vascular resistance remained higher in the chloralose group (a $26 \%$ difference relative to control at $20 \min , p=0.04$ ).

$P V R / S V R$ ratio. No difference between groups was detected in the ratio PVR/SVR throughout the study (Fig. 2).

\section{DISCUSSION}

Chloralose altered basal hemodynamics by producing an increase in heart rate, as well as mean systemic and pulmonary arterial pressure and vascular resistance compared to the conscious control state. During alveolar hypoxia, chloralose induced a higher heart rate, lower cardiac output, and higher systemic and pulmonary vascular resistances.

Although most cardiovascular variables in these studies differed only in response magnitude, systemic vascular resistance 

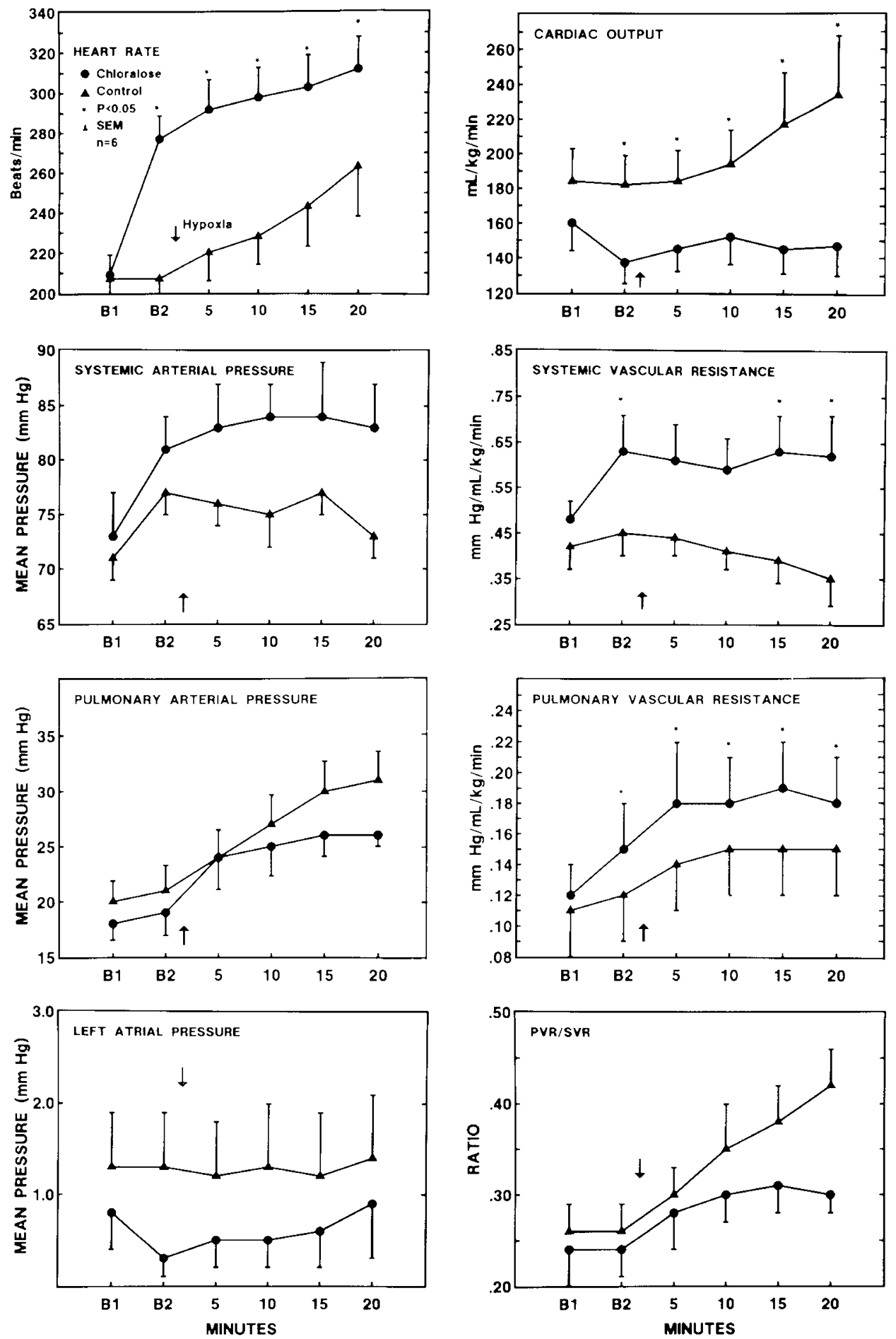

Fig. 2. Hemodynamics after chloralose $\left(30 \mathrm{mg} / \mathrm{kg}\right.$ intravenously, $\bullet$ ) or control saline vehicle $(\mathbf{\Lambda})$ followed by alveolar hypoxia $\left(13-15 \% \mathrm{FiO}_{2}\right)$ in spontaneously breathing lambs. Data are mean \pm SEM. Arrow, onset of alveolar hypoxia. *, difference (ANOVA, $p<0.05$ ) between treatments; $n$ = six paired studies.

during alveolar hypoxia differed in direction of response between the treatment groups. During hypoxia, systemic vascular resistance decreased in the control group and increased in the chloralose-treated group. An altered basal state caused by anesthesia may have important implications for interpreting data from experiments begun after administration of an anesthetic agent; that is, chloralose-induced increases in vascular resistance could alter hemodynamic responses to agents that are given subsequently. For example, the tone-dependent response of the pulmonary circulation is well established $(12,13)$.
Cardiac output failed to increase in response to alveolar hypoxia in the chloralose-treated group, but rose in the control group. Treatment differences in cardiac output must be explained by changes in either heart rate, contractility, preload, or afterload (14). The increased heart rate in chloralose-treated lambs was within the range associated with increased cardiac output and contractility in conscious lambs tested by electrical pacing of the left atrium (15). The heart rate increase in chloralose-treated lambs would be expected to increase cardiac output; therefore, heart rate changes alone do not explain the reduced cardiac 
output. Preload, represented by mean left atrial pressure, did not differ between treatment groups. However, the chloralose-treated group demonstrated increased afterload, indicated by increased systemic vascular resistance, to levels that impair cardiac output both in constantly perfused lamb hearts (16) and in conscious neonatal lambs (17). Therefore, the failure of cardiac output to rise in response to alveolar hypoxia in chloralose-treated lambs must be explained by relationships between hypoxia, increased afterload, and/or reduced contractility. Because our animal model included no direct measure of cardiac contractility, this variable cannot be excluded as a factor; however, mean left atrial pressure did not increase in the chloralose-treated group, as would be expected if a pronounced degree of reduced contractility occurred. Determination of the specific contribution of each variable to the observed effect requires additional study, focused on this question.

Data from previous studies of the cardiovascular effects of chloralose, given without supplemental solvents, on basal hemodynamics have conflicted. Although an increased resting heart rate has been reported with chloralose anesthesia by some investigators (18-23), others have reported no change (7, 11, 24-26); Armstrong et al. (27) reported a lower heart rate. Cardiac output has been reported to range from an increase with (19) or without $(25,26)$ tachycardia, variable changes over time $(11,18)$, a decrease $(18,21)$, and no effect (7). Several studies $(18,22,24$, 28) agree with our observation of a chloralose-induced elevation of systemic arterial pressure; others have reported a depression $(11,26,27)$ or no effect $(7,19,21,25)$.

The variable conclusions regarding the influence of chloralose on basal hemodynamics are best explained by study design, which has varied widely. Study conditions have ranged from mechanical $(7,18,19,21-23,28)$ to spontaneous ventilation (11, $20,24-27)$ and from acute $(18,19,28)$ to chronic instrumentation $(7,11,20-27)$. Moreover, studies have used different doses of chloralose, various supplemental solvents or anesthetic agents, and different species and ages of animals.

Only a few studies have used previously instrumented, conscious, spontaneously ventilating control animals. No study has investigated the influence of chloralose on the pulmonary circulation. Previous studies regarding the effects of anesthesia on hypoxic pulmonary vasoconstriction have concentrated on evaluating the effects of inhalational anesthetic agents (29-32). The influence of intravascular anesthetic agents on hypoxic pulmonary vasoconstriction has been infrequently studied (32-34). With rare exception (35), these studies are complicated by premedication using other anesthetic or analgesic agents and, therefore, have no conscious control state.

Chloralose is often used without additional ventilatory support because it is believed to preserve respiratory drive $(1,2)$. Our study offers some insight into respiratory control during spontaneous ventilation while under chloralose anesthesia. Respiratory rate slowed in our animals, indicating that respiratory timing mechanisms may be altered by the $30-\mathrm{mg} / \mathrm{kg}$ dose of chloralose we used. Arterial carbon dioxide tension remained unchanged, suggesting that normal minute ventilation was maintained by hyperpnea under chloralose anesthesia. Follow-up studies to determine whether alterations in tidal vol in the chloralose group would affect intrathoracic pressure measurements are indicated. The reduced arterial oxygen tension in chloralose-treated lambs under both basal and posthypoxic conditions suggests that altered airway closure may have caused reduced functional residual capacity and lower arterial oxygen tension, as has been demonstrated with other anesthetics (36-38). Differences in ventilationperfusion matching between treatment groups could also account for this finding. Finally, we identified a statistically lower $\mathrm{pH}$ in chloralose-treated lambs in the basal study only, suggesting that a mild metabolic acidosis developed. Only Arfors et al. (20), noting a minimal mixed acidosis in dogs, have previously reported chloralose-induced effects on arterial blood gas tensions in spontaneously breathing animals.
Because changes in arterial blood gas tensions were detected only after changes in hemodynamics occurred, the hemodynamic effects of chloralose were probably not secondary to anesthesiainduced changes in arterial blood gas tensions. Moreover, no chloralose-treated lamb demonstrated a hemodynamically important metabolic acidosis to indicate that an oxygen debt developed in either study. These obesrvations suggest that the pulmonary circulatory effects of chloralose are primary, not secondary to alterations in arterial blood gas tensions.

Finally, despite the published opinion that animals cannot maintain normal function after chloralose anesthesia (39), the lambs returned to their ewes after awakening from this dose of chloralose and thrived, both immediately and for several wk.

Chloralose anesthesia has been recommended as ideal for cardiovascular experimentation $(1,2)$. Under paired conditions, without the confounding variables of supplemental solvents, anesthetics, or mechanical ventilation, we have demonstrated that several hemodynamic alterations occur in postnatal lambs after chloralose. Our data suggest that conclusions drawn from observations of responses of the pulmonary and systemic circulations made while animals are chloralose-anesthetized may inaccurately predict responses of unanesthetized animals.

Acknowledgments. The authors are grateful to Dr. Thomas N. Hansen for his counsel, Ms. Diana Lyles and Mr. Jay W. Meyer for their technical assistance, and Ms. Jackie McDonald and Ms. Rose Carpenter for secretarial support.

\section{REFERENCES}

1. Greisheimer EM 1965 The circulatory effects of anesthetics. In: Hamilton WF (ed) Handbook of Physiology-Circulation. Williams \& Wilkins, Baltimore, pp 2483-2485

2. Strobel GE, Wollman H 1969 Pharmacology of anesthetic agents. Fed Proc 28:1386-1403

3. Balis GU, Monroe RR 1964 The pharmacology of chloralose. Psychopharmacolog (Berlin) 6:1-30

4. Booth NH 1977 Intravenous and other parenteral anesthetics. In: Booth $\mathrm{NH}$ McDonald LE (eds) Veterinary Pharmacology and Therapeutics. Iowa State University Press, Ames, IA, pp 297-298

5. Altura BT, Altura BM 1975 Pentobarbital and contraction of smooth muscle. Am J Physiol 229:1635-1640

6. Vatner SF, Braunwald E 1975 Cardiovascular control mechanisms in the conscious state. N Engl J Med 293:970-976

7. Zimpfer M, Sit SP, Vatner SF 1981 Effects of anesthesia on the canine carotid chemoreceptor reflex. Circ Res 48:400-406

8. Drummond WH, Webb IB, Purcell KA 1981 Cardiopulmonary response to dopamine in chronically catheterized neonatal lambs. Pediatr Pharmacol 1:347-356

9. Covert RF, Drummond WH, Gimotty PA 1988 Chloralose alters circulatory response to alpha receptor stimulation and blockade. Am J Physiol 255 (Heart Circ Physiol 24):H419-H425

10. Lock JE, Hamilton F, Luide H, Coceani F, Olley PM 1980 Direct pulmonary vascular responses in the conscious newborn lamb. J Appl Physiol: Respir Environ Exerc Physiol 48:188-196

11. Cox RH 1972 Influence of chloralose anesthesia on cardiovascular function in trained dogs. Am J Physiol 223:660-667

12. Fishman AP 1985 Pulmonary circulation. In: Fishman AP (ed) Handbook of Physiology: The Respiratory System, vol 1: Circulation and Non-Respiratory Functions. American Physiological Society, Bethesda, MD, p 123

13. McMurtry IF, Raffestin B 1987 Potential mechanisms of hypoxic pulmonary vasoconstriction. In: Will JA, Dawson CA, Weir EK, Buckner CK (eds) The Pulmonary Circulation in Health and Disease. Academic Press, New York, p 456

14. Braunwald E, Sonnenblick EH, Ross J 1984 Contraction of the normal heart In: Braunwald E (ed) Heart Disease: A Textbook of Cardiovascular Medicine. WB Saunders Co, Philadelphia, pp 430-438

15. Fisher DJ, Gross DM 1983 The effect of atrial pacing-induced tachycardia on left ventricular contractile function in conscious newborn and adult sheep. Pediatr Res 17:651-656

16. Downing SE, Talner NS, Gardner TH 1965 Ventricular function in the newborn lamb. Am J Physiol 208:931-937

17. Feltes TF, Hansen TN, Martin CG, LeBlanc AL, Smith S, Giesler ME 1987 The effects of dopamine infusion on regional blood flow in newborn lambs. Pediatr Res 21:131-136

18. Bass BG, Buckley NM 1966 Chloralose anesthesia in the dog: a study of drug actions and analytical methodology. Am J Physiol 210:854-862

19. Charney AN, Bass BG, Buckley NM 1970 Cardiovascular effects of chloralose in catecholamine-depleted or receptor-blocked dogs. Arch Int Pharmacodyn 
185:397-405

20. Arfors KE, Arturson G, Malmberg P 1971 Effect of prolonged chloralose anesthesia on acid-base balance and cardiovascular functions in dogs. Acta Physiol Scand 81:47-53

21. Cox RH, Bagshaw RJ 1979 Influence of anesthesia on the response to carotid hypotension in dogs. Am J Physiol 237 (Heart Circ Physiol 6):H424-H432

22. Stephenson RB, Donald DE 1980 Reflexes from isolated carotid sinuses of intact and vagotomized conscious dogs. Am J Physiol 238 (Heart Circ Physiol 7): $\mathrm{H} 815-\mathrm{H} 822$

23. O'Connor SE, Smith GW, Brown RA 1982 Comparison of the cardiovascular actions of N,N-Di-n-propyl dopamine and sodium nitroprusside in conscious and chloralose-anaesthetised dogs. J Cardiovasc Pharmacol 4:493-499

24. Duchenne-Marullaz P, Fabry-Delaique R, Gueorguiev G, Kantelip JP 1982 Influence of chloralose and pentobarbitone sodium on atrioventricular conduction in dogs. Br J Pharmacol 77:309-317

25. Halkola L, Koivikko A, Lansimies E 1974 Hemodynamic effects of chloralose and propranolol in dogs. Acta Physiol Scand 90:505-508

26. Van Citters RL, Franklin DL, Rushmer RF 1964 Left ventricular dynamics in dogs during anesthesia with alpha-chloralose and sodium pentobarbital. Am J Cardiol 13:349-354

27. Armstrong GG Jr, Porter H Jr, Langston JB 1961 Alteration of carotid occlusion response by anesthesia. Am J Physiol 201:897-900

28. Brown RV, Hilton JG 1956 The effectiveness of the baroreceptor reflexes under different anesthetics. J Pharmacol Exp Ther 118:198-203

29. Marshall C. Lindgren L, Marshall BE 1984 Effects of halothane, enflurane, and isoflurane on hypoxic pulmonary vasoconstriction in rat lungs in vitro. Anesthesiology 60:304-308

30. Sykes MK. Davies DM, Chakrabarti MK, Loh L 1973 The effects of halothane, trichloroethylene and ether on the hypoxic pressor response and pulmonary vascular resistance in the isolated, perfused cat lung. Br J Anaesth 45:655663

31. Sykes MK, Loh L, Seed RF, Kafer ER, Chakrabarti MK 1972 The effect of inhalational anesthetics on hypoxic pulmonary vasoconstriction and pulmonary vascular resistance in the perfused lungs of the dog and cat. $\mathrm{Br}$ J monary vascular resistar
Anaesth 44:776-788

32. Bjertnaes LJ 1977 Hypoxia-induced vasoconstriction in isolated perfused lungs exposed to injectable or inhalation anesthetics. Acta Anaesthesiol Scand 21:133-147

33. Bindslev L, Cannon D, Sykes MK 1986 Effect of lignocaine and nitrous oxide on hypoxic pulmonary vasoconstriction in the dog constant-perfused left lower lobe preparation. Br J Anaesth 58:315-320

34. Bjertnaes L, Hauge A, Kriz M 1980 Hypoxia-induced pulmonary vasoconstriction: effects of fentanyl following different routes of administration. Acta Anaesthesiol Scand 24:53-57

35. Price HL, Cooperman LH, Warden JC, Morris JJ, Smith TC 1969 Pulmonary hemodynamics during general anesthesia in man. Anesthesiology 30:629636

36. Rehder K, Sessler AD, Marsh HM 1975 General anesthesia and the lung. Am Rev Respir Dis 112:541-563

37. Hewlett AM, Hulands GH, Nunn JF, Heath JR 1974 Functional residual capacity during anesthesia II: Spontaneous respiration. Br J Anaesth 46:486494

38. Fairley HB 1972 Airway closure. Anesthesiology 36:529-532

39. Gross DR 1985 Cardiovascular effects of intravenous anesthetic agents. In: Gross DR (ed) Animal Models in Cardiovascular Research. Martinus Nijhoff Publishers, Boston. pp 197-243 